\title{
Measurement of D-Dimer Levels in Hyperthyroidism Patients
}

\author{
Hazar Abdalmutalib Mohmed, Nasr Eldeen Ali Mohammed* \\ Department of Haematolgy, Faculty of Medical Laboratory Sciences, Alneelain University, Khartoum, Sudan \\ Email: *Nasralimohammed@yahoo.com
}

Received 28 May 2016; accepted 12 August 2016; published 15 August 2016

Copyright (C) 2016 by authors and OALib.

This work is licensed under the Creative Commons Attribution International License (CC BY). http://creativecommons.org/licenses/by/4.0/

(c) () Open Access

\begin{abstract}
Background: Haemostaticab normalities were associated with hyper thyrodism patients. This study aimed to assess the D-dimer levels which indicate the hypercoagulable state in Sudanese patients with hyper thyrodism. Material and Methods: A descriptive analytical case study was conducted in faculty of medical laboratory science, Alneelain University, Khartoum, Sudan. A total of 80 participants were selected for this study, 40 of them were patient known diagnosed by hyperthyroidism as a test group; $20(50 \%)$ were female and 20 (50\%) were male; their mean age 36.3 years. Other 40 participants were normal healthy individual as control group. The plasma D-dimer level was measured by using semi-automated coagulometer (MISPA-i2Reagent-SWITZERLAND). Data were analyzed by using statistical package for social sciences (SPSS) Version 20. Results: In this study, the plasma D-dimer level has statistically significantly higher in hyperthyroidism patient compared to normal healthy control group (mean \pm SD $0.5008 \pm 0.239$ vs. $0.5 \pm 0.618 \mathrm{mg} / \mathrm{dl}$ with $P$ value 0.00 ), respectively. Conclusions: The present study revealed that the $D$-dimer levels were statistically significant higher in hyper thyroid patients.
\end{abstract}

\section{Keywords}

Hyperthyroidism, Coagulation, D-Dimer, Sudan

Subject Areas: Hematology

\section{Introduction}

The thyroid gland is found in the neck, below the laryngeal prominence. This is formed by angle of the thyroid cartilage that surrounds the larynx. The thyroid gland controls how quickly the body uses energy, makes proteins, and controls the body's sensitivity to other hormones. It participates in these processes by producing thyroid hormones, the principal ones being triodothyronine (T3) and thyroxin (T4). These hormones regulate the

*Corresponding author. 
growth and rate of function of many other systems in the body. T3 and T4 are synthesized from iodine and tyrosine. The thyroid also produces calcitonin, which plays a role in calcium homeostasis [1]. Hormonal output from the thyroid is regulated by thyroid-stimulating hormone (TSH) produced by the anterior pituitary, which itself is regulated by thyrotropin-releasing hormone (TRH) produced by the hypothalamus. Any disturbances in thyroid hormones lead to these diseases: hypothyroidism, hyperthyroidism, thyroid nodule and thyroid neoplasm. Hypothyroidism happens when the thyroid gland does not produce enough thyroid hormone. The most common form of hypothyroidism is Hashimoto's thyroiditis [2] [3]. Hyperthyroidism develops when the thyroid gland becomes overactive and produces too much thyroid hormone it produces hormones called T3 and T4. They control the body's metabolism. This condition is most common caused by the development of Graves's disease, an auto immune in which anomalous antibodies stimulate the thyroid to secrete excessive quantities of thyroid hormone [4]. Thyroid disorders are common endocrine disorders encountered in the African continent. Environmental and nutritional factors are often implicated in the occurrence of some thyroid disorders that occur in this part of the world [5]. In the United States, hyperthyroidism affects about $1.2 \%$ of the population [6]. About half of these cases have obvious symptoms while the other half does not [7]. It occurs between two and ten times more often in women [8]. The disease is more common in those over the age of 60 years [8].

The presentation of thyrotoxicosis is variable among patients. Thyrotoxicosis leads to an apparent increase in sympathetic nervous system symptoms. Younger patients tend to exhibit symptoms of sympathetic activation, such as anxiety, hyperactivity, and tremor, while older patients have more cardiovascular symptoms, including dyspnea and atrial fibrillation with unexplained weight loss [9].

Several pathophysiological mechanisms have been suggested to underlie the relation between thyroid hormone excess and hemostasis. One of these mechanisms is the activation of the immune system in thyroid disease [10] [11]. Hyperthyroidism is associated with a hypercoagulablestate [12] [13].

\section{Material and Methods}

A descriptive analytical case study was conducted in faculty of medical laboratory science, Alneelain University, Khartoum, Sudan. A total of 80 participants were selected for this study, 40 of them were patient known diagnosed by hyperthyroidism as a test group; 20 (50\%) were female and 20 (50\%) were male; their mean age 36.3 years. Other 40 participants were normal healthy individual as control group; their mean age and gender were matched with patients group. The ethical consent was taken from all subject enrolled in this study. Blood sample was collected from all participants by clean vein puncture. Nine volume of fresh blood will be collected in one volume in tube containing $200 \mu \mathrm{l}$ of $3.2 \%$ tri sodium citrate solution and platelet poor plasma was prepared by centrifuged at $3000 \mathrm{rpm}$ for 15 minutes. The plasma D-dimer level was measured by using semi-automated coagulometer using (MISPA- $\mathrm{i}_{2}$ Reagent-SWITZERLAND); this reagent is used for in vitro quantitative determination of fibrin degradation product D-dimer in human plasma by Nephelometric Immunoassay that utilizes antibody coated latex particles. In the presence of D-dimer, the particles aggregate and light scattering increases. The increase in scattering is proportional to the amount of D-dimer in sample, and in the procedure was carried out as per the manufacturer instructions.

None of the patients had a history of coagulopathy disease that could have disrupt the coagulation-fibrinolytic balance. This study was approved by scientific research committee, faculty of Medical laboratory sciences, Alneelain University. The informed consent was obtained from all participants in this study before the samples were collection. Data were analyzed by using statistical package for social sciences (SPSS) version 20.T. test was used for comparison between different study groups. The level of statistical significance was set at less than 0.05 .

\section{Result}

This prospective case control study done in February 2016. A total of 80 subject were included in this study 40 were patients known diagnosed by hyperthyroidism as a test group 20 (50\%) were female and 20 (50\%) were male; their mean age 36.3 years. Others 40 subject were normal healthy individual as normal control group; their mean age and gender were similar with patients group.

The current study revealed that the D-dimer levels were statistically significantly higher in patients with hyperthyroidism compared with normal health control group, (The mean and SD $0.5008 \pm 0.239$ vs. $0.215 \pm$ $0.618 \mathrm{mg} / \mathrm{dlP}$ value 0.00 ) respectively (Table 1 ).

Based on the gender and age this study found that there was no statistically significant different between age, gender and levels of D-dimer (P value 0.15 and 0.78 ) respectively. 
Table 1. The association of D-dimer levels, TSH, T3 and T4 in patients with hyperthyroidism and normal control.

\begin{tabular}{cccc}
\hline Case & Patient Mean \pm SD & Control Mean \pm SD & P Value \\
Parameters & $0.5008 \pm 239$ & $0.215 \pm 0.618$ & 0.00 \\
\hline D-Dimer & $0.08 \pm 0.20$ & $1.77 \pm 0.849$ & 0.00 \\
TSH & $305.6 \pm 127.5$ & $149.25 \pm 30.34$ & 0.00 \\
T3 & $15.8 \pm 3.65$ & $7.34 \pm 1.74$ & 0.00 \\
\hline
\end{tabular}

\section{Discussion}

This study aimed to assess the plasma D-dimer level which indicates the hypercoagulable state in the patient with hyper thyrodsim. Many hypothesis suggest that a strong correlation between the elevation of thyroid hormone and abnormal homeostasis. D-dimer is a fragment of cross-linked fibrin and a good biochemical marker of thrombosis [14].

The current study revealed that the D-dimer level was statistically significantly higher in patients with hyperthyroidism compared with those normal healthy control groups (P value 0.00). This finding was in agreement with study done in 2001 by Chadevarianet.al who reported the D-dimer level was statistically significantly higher in patients with hyperthyroidism. The interesting result of this study was also in concordance with recent study published in 2011 cited by Debeij J., Suzanne C. C., van Zaane B. et al. who found the D-dimer levels was significantly higher in hyperthyroidism patients [15] [16].

The present study showed that a significant correlation between thyroid hormone T3, T4 and plasma D-dimer level with $\mathrm{P}$ value 0.00 . This findings was agree with Erem et al. and study done by Burggraaf et al. who reported that the T3, T4 was associated with elevation plasma D-dimer level in hyperthyroid patients [17] [18]. Our findings was in contrast with studies cited by Chadevarian et al. [19], Debeij J., Suzanne C. C., van Zaane B. et al. [16] and Yango et al. [14]. This may be attributed to our patients were new cases in this study or might be due to ethnic background.

\section{Conclusion}

Sudanese patients with hyperthyroidism presented a state of hypercoagulability.

\section{References}

[1] Adam, S.S., Key, N.S. and Greenberg, C.S. (2009) Prospects. Blood, 113, 2878-2887. http://dx.doi.org/10.1182/blood-2008-06-165845

[2] (2011) General Practice Notebook > D-Dimer.

[3] Suzuki, T., Distante, A. and Eagle, K. (2010) Biomarker-Assisted Diagnosis of Acute Aortic Dissection: How Far We Have Come and What to Expect. Current Opinion in Cardiology, 25, 541-545. http://dx.doi.org/10.1097/HCO.0b013e32833e6e13

[4] Wells, P.S., Anderson, D.R., Rodger, M., Forgie, M., Kearon, C., Dreyer, J., Kovacs, G., Mitchell, M., Lewandowski, B. and Kovacs, M.J. (2003) Evaluation of D-Dimer in the Diagnosis of Suspected Deep-Vein Thrombosis. The New England Journal of Medicine, 349, 1227-1235. http://dx.doi.org/10.1056/NEJMoa023153

[5] Ogbera, A.O. and Kuku, S.F. (2011) Epidemiology of Thyroid Diseases in Africa. Indian Journal of Endocrinology and Metabolism, 15, S82-S88. http://dx.doi.org/10.4103/2230-8210.83331

[6] Bahn, R.S., et al. (2011) Hyperthyroidism and Other Causes of Thyrotoxicosis: Management Guidelines of the American Thyroid Association and American Association of Clinical Endocrinologists. Thyroid, 21, 593-646. http://dx.doi.org/10.1089/thy.2010.0417

[7] Devereaux, D. and Tewelde, S.Z. (2014) Hyperthyroidism and Thyrotoxicosis. Emergency Medicine Clinics of North America, 32, 277-292. http://dx.doi.org/10.1016/j.emc.2013.12.001

[8] (2015) Hyperthyroidism. www.niddk.nih.gov

[9] Frost, L., Vestergaard, P. and Mosekilde, L. (2004) Hyperthyroidism and Risk of Atrial Fibrillation or Flutter: A Population-Based Study. Archives of Internal Medicine, 164, 1675-1678. http://dx.doi.org/10.1001/archinte.164.15.1675 
[10] Franchini, M., Lippi, G., Manzato, F., et al. (2010) Thyroid-Associated Autoimmune Coagulation Disorders. Journal of Thrombosis and Thrombolysis, 29, 87-91. http://dx.doi.org/10.1007/s11239-009-0327-1

[11] Hoylaerts, M.F., Thys, C., Arnout, J., et al. (1998) Recurrent Arterial Thrombosis LINKED to Autoimmune Antibodies Enhancing von Willebrand Factor Binding to Platelets and inducing Fc Gamma RII Receptor-Mediated Platelet Activation. Blood, 91, 2810-2817.

[12] Squizzato, A., Romualdi, E., Buller, H.R., et al. (2007) Clinical Review: Thyroid Dysfunction and Effects on Coagulation and Fibrinolysis: A Systematic Review. The Journal of Clinical Endocrinology \& Metabolism, 92, 2415-2420. http://dx.doi.org/10.1210/jc.2007-0199

[13] Vescovi, P.P., Favaloro, E.J., Lippi, G., et al. (2011) The Spectrum of Coagulation Abnormalities in Thyroid Disorders. Seminars in Thrombosis and Hemostasis, 37, 7-10. http://dx.doi.org/10.1055/s-0030-1270065

[14] Lip, G.Y. and Lowe, G.D. (1995) Fibrin D-Dimer: A Useful Clinical Marker of Thrombogenesis? Clinical Science, 89, 205-214. http://dx.doi.org/10.1042/cs0890205

[15] Chadarevian, R., Bruckert, E., Leenhardt, L., et al. (2001) Components of the Fibrin Lytic System Are Differently Altered In Moderate and Severe Hypothyroidism. The Journal of Clinical Endocrinology \& Metabolism, 86, 732-737. http://dx.doi.org/10.1210/jcem.86.2.7221

[16] Debeij, J., Suzanne, C.C., van Zaane, B., et al. (2010) The Effect of Changes in Thyroxine and Thyroid Stimulating Hormone Levels on the Coagulation System. Journal of Thrombosis and Haemostasis, 8, 2823-2826. http://dx.doi.org/10.1111/j.1538-7836.2010.04054.x

[17] Erem, C., Ersoz, H.O., Karti, S.S., et al. (2002) Blood Coagulation and Fibrinolysis in Patients with Hyperthyroidism. Journal of Endocrinological Investigation, 25, 345-350. http://dx.doi.org/10.1007/bf03344016

[18] Burggraaf, J., Lalezari, S., Emeis, J.J., et al. (2001) Endothelial Function in Patients with Hyperthyroidism before and after Treatment with Propranolol and Thiamazol. Thyroid, 11, 153-160. http://dx.doi.org/10.1089/105072501300042820

[19] Yango, J., Alexopoulou, O., Eeckhoudt, S., et al. (2011) Evaluation of the Respective Influence of Thyroid Hormones and TSH on Blood Coagulation Parameters after Total Thyroidectomy. European Journal of Endocrinology, 164, 599603. http://dx.doi.org/10.1530/EJE-10-0837

\section{Submit or recommend next manuscript to OALib Journal and we will provide best service for you:}

- Publication frequency: Monthly

- 9 subject areas of science, technology and medicine

- Fair and rigorous peer-review system

- Fast publication process

- Article promotion in various social networking sites (LinkedIn, Facebook, Twitter, etc.)

- Maximum dissemination of your research work

Submit Your Paper Online: Click Here to Submit

Contact Us: service@oalib.com 